\title{
Pt(II)-Coordinated Tricomponent Self-Assemblies of Tetrapyridyl Porphyrin and Dicarboxylate Ligands: Are They Really 3D Prisms or 2D Bow Ties?
}

\author{
Paola A. Benavides, ${ }^{a}$ Monica A. Gordillo, ${ }^{\mathrm{a}}$ Ashok Yadav, ${ }^{\mathrm{a}}$ M. Andrey Joaqui-Joaqui, ${ }^{\mathrm{b}}$ and Sourav Saha ${ }^{\mathrm{a}, 1}$

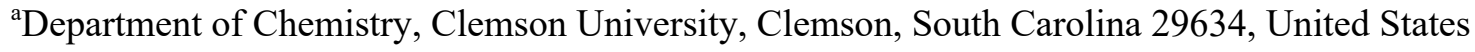 \\ ${ }^{\mathrm{b}}$ Department of Chemistry, University of Minnesota, Minneapolis, MN 55455, United States \\ ${ }^{1}$ To whom correspondence may be addressed. Email: $\underline{\text { souravs@clemson.edu }}$
}

\begin{abstract}
Thermodynamically favored heteroleptic coordination of Pt(II) ions with one aza- and another oxocoordinating ligand yield tricomponent supramolecular coordination complexes (SCCs) that possess much greater structural complexity and functional diversity than traditional bicomponent SCCs containing only one of the ligands. Herein, we demonstrate that heteroleptic coordination of tetrapyridyl porphyrins ( $\mathrm{M}^{\prime} \mathrm{TPP}, \mathrm{M}^{\prime}=\mathrm{Zn}$ or $\mathrm{H}_{2}$ ) and various dicarboxylate ligands (XDC) having different lengths and rigidity with cis- $\left(\mathrm{Et}_{3} \mathrm{P}\right)_{2} \mathrm{Pt}^{\mathrm{II}}$ corners actually yields bow tie $(\bowtie)$-shaped tricomponent $\left[\left\{c i s-\left(\mathrm{Et}_{3} \mathrm{P}\right)_{2} \mathrm{Pt}\right\}_{4}\left(\mathrm{M}^{\prime} \mathrm{TPP}\right)(\mathrm{XDC})_{2}\right]^{4+}$ complexes featuring a M'TPP core and two parallel XDC linkers held together by four heteroligated $\mathrm{Pt}^{\mathrm{II}}(\mathrm{N}, \mathrm{O})$ corners. Although previous reports had claimed that the self-assembly of these three components produced tetragonal prisms having two cofacial M'TPP planes connected by four XDC linkers via eight $\mathrm{Pt}^{\mathrm{II}}(\mathrm{N}, \mathrm{O})$ corners, our extensive ${ }^{1} \mathrm{H},{ }^{31} \mathrm{P}$, and 2D NMR, ESI-MS, X-ray crystallographic, and computational studies unequivocally demonstrated that in reality, no such prism was formed, because instead of connecting two cofacial M'TPP ligands, the XDC linkers actually bridged two adjacent pyridyl termini of an M'TPP ligand via shared $\mathrm{Pt}^{\mathrm{II}}(\mathrm{N}, \mathrm{O})$ corners, forming bow tie complexes. In addition to direct crystallographic evidence, the NMR spectra of these complexes revealed that the M'TPP ligands contained two distinct sets of pyrrole protons (4 each) — those located inside the triangles were shielded by and coupled to adjacent XDC linkers, whereas the exposed ones were not - the unmistakable signs of bow tie structures instead of prisms. Thus, this work not only unveiled novel supramolecular architecture, but also accurately defined the actual structures and compositions of M'TPP-based tricomponent SCCs.
\end{abstract}

\section{INTRODUCTION}

Owing to the dynamic, directional, and self-selecting/rectifying nature of metal-ligand coordination bonds, metal-driven self-assembly processes have emerged as one of the most attractive and versatile tools of supramolecular chemistry, yielding myriads of supramolecular coordination complexes (SCCs) ranging 
from discrete metallacycles ${ }^{1-10}$ and cages $^{11-23}$ to extended coordination polymers and metal-organic frameworks ${ }^{24-26}$ over several decades. To obtain the target SCCs and to avoid statistical mixtures of different possibilities, only one rigid organic ligand is typically introduced to a metal ion at appropriate stoichiometry that yield bicomponent coordination complexes. However, the resulting bicomponent SCCs often lack the structural and functional diversity and tunability needed for various advanced applications. Expanding the scope of coordination-driven self-assembly strategies, several researchers have recently discovered ${ }^{26-56}$ that cis-capped $\mathrm{Pt}(\mathrm{II})$ and $\mathrm{Pd}$ (II) corners can simultaneously bind a carboxylate and a pyridyl ligands, preferentially yielding thermodynamically favored heteroleptic $\mathrm{Pt}(\mathrm{N}, \mathrm{O})$ complexes instead of two different homoleptic complexes. ${ }^{29-34,47-53}$ Furthermore, when two different homoleptic $\mathrm{Pt}^{\mathrm{II}}\left(\mathrm{COO}^{-}\right)_{2}$ and $\mathrm{Pt}^{\mathrm{II}}$ (pyridyl $)_{2}$ complexes were mixed together at an appropriate stoichiometry, they spontaneously reorganized into thermodynamically more stable heteroleptic $\mathrm{Pt}(\mathrm{N}, \mathrm{O})$ complexes. ${ }^{30,32,33}$ These revelations paved the door for metal-driven self-assembly of tricomponent metallacycles and cages containing two complementary ligands that could further diversify their structures, compositions, properties, and functions.

While it is fairly straightforward to assemble 2:2:4 tricomponent rectangles ${ }^{30,32,41}$ having two parallel dicarboxylate and two parallel dipyridyl arms connected by four heteroligated $\mathrm{Pt}^{\mathrm{II}}(\mathrm{N}, \mathrm{O})$ corners, the formation of 2:4:8 tricomponent tetragonal prisms featuring two cofacial tetratopic (tetrapyridyl or tetracarboxylate) ligands and four complementary ditopic (dicarboxylate or dipyridyl) linkers requires the latter to intermolecularly connect the tips of two separate cofacial tetratopic ligands via eight heteroleptic $\mathrm{Pt}(\mathrm{N}, \mathrm{O})$ corners $^{30,32,35,36}$ instead of intramolecularly bridging two adjacent tips of the same tetratopic ligand. If a ditopic linker intramolecularly bridged two adjacent binding sites of the tetratopic ligand via shared $\operatorname{Pt}(\mathrm{N}, \mathrm{O})$ corners, then entropically more favored 1:2:4 bow tie $(\bowtie)$ complexes would be formed instead of 2:4:8 tetragonal prisms. ${ }^{54}$ Nevertheless, Stang and coworkers have recently claimed ${ }^{30,33,34}$ that Pt(II)-driven tricomponent self-assembly of tetrapyridyl porphyrin ( $\mathrm{M}^{\prime} \mathrm{TPP}, \mathrm{M}^{\prime}=\mathrm{Zn}$ - or $\mathrm{H}_{2}$ ) and various aromatic and aliphatic dicarboxylate (XDC) linkers having varied length and rigidity yielded tetragonal prisms [ $\{$ cis$\left.\left.\left(\mathrm{Et}_{3} \mathrm{P}\right)_{2} \mathrm{Pt}\right\}_{8}\left(\mathrm{M}^{\prime} \mathrm{TPP}\right)_{2}(\mathrm{XDC})_{4}\right]^{8+}$ featuring two parallel M'TTP faces and four XDC pillars connected by eight heteroligated $\mathrm{Pt}^{\mathrm{II}}(\mathrm{N}, \mathrm{O})$ corners. These complexes preserved the photophysical properties of M'TPP chromophores $^{33}$ and displayed promising applications in cancer photodynamic therapy ${ }^{39}$ and guest encapsulation. ${ }^{55}$ Encouraged by these promising reports, ${ }^{30,33,34,39,56}$ we had attempted to construct bichromophoric tetragonal prisms consisting of two M'TPP faces and four dicarboxylate linkers having complementary redox- and optically active aromatic cores, such as naphthalene- and perylene diimides that could support ligand-to-ligand photoinduced electron and/or energy transfer events. Surprisingly, none of our attempts to build such M'TPP-based bi-chromophoric prisms based on the reported protocols was successful despite the fact that the lengths of our XDC linkers were much longer than the distances between 
the two adjacent pyridyl-N atoms of free M'TPP ligands $\left(d_{\mathrm{N}-\mathrm{N} / \text { free }}=10.9 \AA\right)$, which precluded the possibility of intramolecular bridging of two adjacent pyridyl groups via heteroligated $\mathrm{Pt}^{\mathrm{II}}(\mathrm{N}, \mathrm{O})$ corners. Prompted by these unexpected outcomes, we took a closer look at the ${ }^{1} \mathrm{H}$ NMR spectra of the M'TPP-based proposed tetragonal prisms reported in the literature, ${ }^{30,33,34,56}$ which actually displayed two distinct singlets (1:1 ratio) for pyrrole protons - one set of four pyrrole protons were significantly more shielded than the other four (in contrast, all eight pyrrole protons of free M'TPP ligands are chemically equivalent and show one singlet) - indicating that in these tricomponent SCCs, the pyrrole rings of M'TPP ligands were no longer chemically equivalent, i.e., they were located in two different environments. These reported ${ }^{1} \mathrm{H}$ NMR signals appeared to be at odds with the proposed tetragonal prism formation because all pyrrole rings of M'TPP in the proposed prisms should have been located in the same chemical environment and displayed the same NMR signal. ${ }^{47-49,53,55}$ On the other hand, the observed ${ }^{1} \mathrm{H}$ NMR signals of two distinct pyrrole protons would have made a perfect sense if the Pt(II)-driven tricomponent self-assembly of M'TPP and XDC ligands yielded 2D bow tie $(\bowtie)$ complexes, a genuine possibility that was previously overlooked. In this scenario, the two opposite pyrrole rings of M'TPP would be located inside two isosceles triangles formed by two parallel XDC linkers and therefore shielded accordingly, while the other two opposite pyrrole rings would remain exposed and not shielded by the XDC linkers. These inconsistencies prompted us to carefully examine whether or not the Pt(II)-driven self-assembly processes of M'TPP and XDC ligands do actually produce tricomponent prisms or yield an entirely different supramolecular architecture, such as tricomponent bow ties having the same ratio $(4: 1: 2)$ of the three components.

Herein, we report self-assembly and in-depth characterization of eight novel bow tie complexes $\left[\left\{\text { cis- }\left(\mathrm{Et}_{3} \mathrm{P}\right)_{2} \mathrm{Pt}\right\}_{4}\left(\mathrm{M}^{\prime} \mathrm{TPP}\right)(\mathrm{XDC})_{2}\right] \cdot 4(\mathrm{TfO})\left(\right.$ Scheme 1) composed of $\mathrm{M}^{\prime} \mathrm{TPP}$ ligands $\left(\mathrm{M}^{\prime}=\mathrm{Zn}\right.$ and $\left.\mathrm{H}_{2}\right)$ and four different XDC linkers, namely 1,6-hexane-, 4,4'-biphenyl-, 1,4-benzene-, and 2,6-naphthalenedicarboxylates (HDC, BPDC, BDC, and NDC). While the ${ }^{1} \mathrm{H},{ }^{31} \mathrm{P}$, and 2D (COSY and ROESY) NMR and ESI-MS analyses of these complexes presented telltale signs of their bow tie structures and ruled out prism formation, the most direct and compelling evidence came from their single-crystal structures, which revealed that each complex was composed of an M'TPP core and two parallel XDC linkers, which were connected by four heteroligated $\left(\mathrm{Et}_{3} \mathrm{P}\right)_{2} \mathrm{Pt}^{\mathrm{II}}(\mathrm{N}, \mathrm{O})$ corners. Notably, this was the first time, the single-crystal structures of such M'TPP-based tricomponent SCCs could be determined. In addition, the energyminimized structures of these bow tie complexes were in good agreement with the experimental results, which collectively shined light on why the M'TPP ligands actually formed bow tie complexes instead of tetragonal prisms. 
Scheme 1. Pt(II)-driven self-assembly of $M^{\prime}$ TPP ligands $\left(M^{\prime}=\mathrm{Zn}\right.$ or $\left.\mathbf{H}_{2}\right)$ and four different XDC linkers (HDC, BPDC, BDC, and NDC) exclusively yielded novel bow tie complexes [\{cis$\left.\left(\mathrm{Et}_{3} \mathrm{P}\right)_{2} \mathrm{Pt}_{4}\left(\mathrm{M}^{\prime} \mathrm{TPP}\right)(\mathrm{XDC})_{2}\right] \cdot 4(\mathrm{TfO})(\mathrm{BT1}-\mathrm{BT} 4$ and BT1'-BT4'). No tetragonal prism was formed irrespective of the length and rigidity of the XDC linkers.

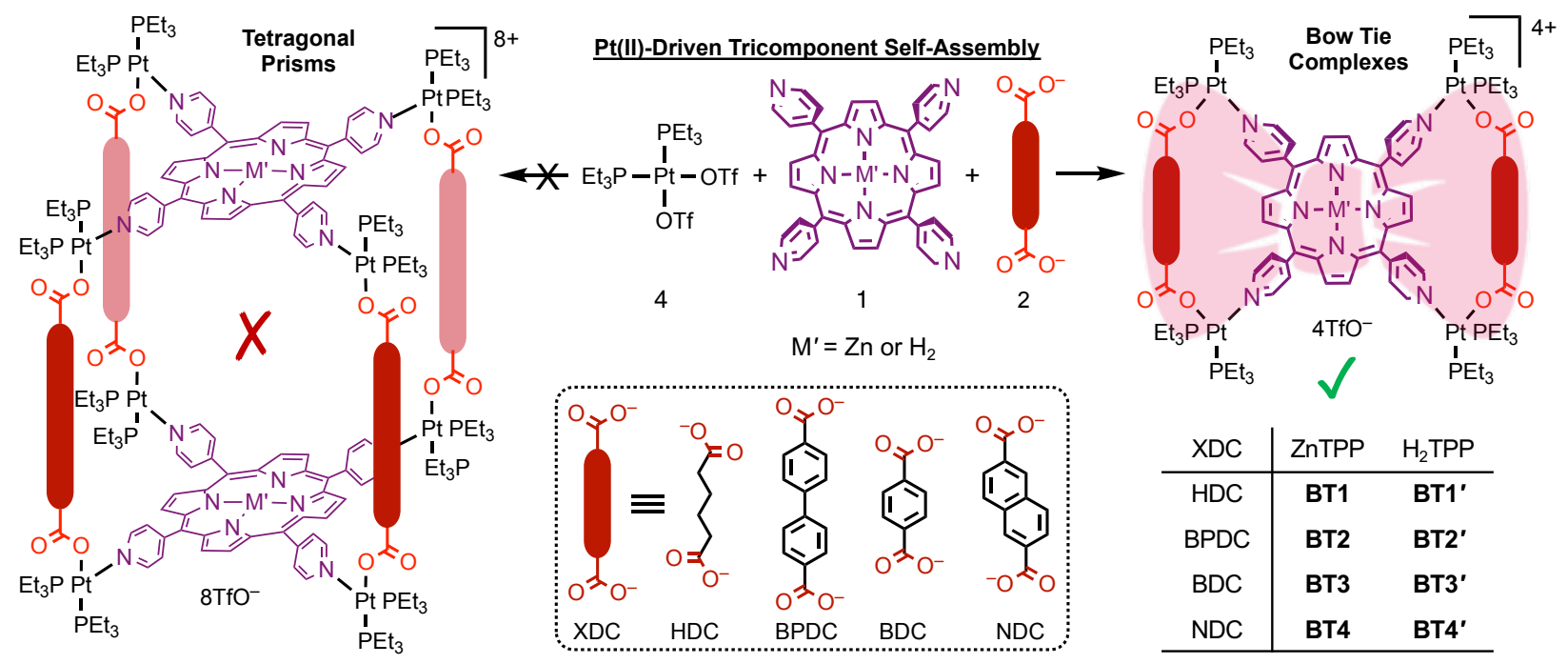

\section{RESULTS AND DISCUSSION}

Heteroleptic Coordination-Driven Self-Assembly of M'TPP-Based Tricomponent Bow Ties ( $\bowtie$ ). To determine whether heteroleptic coordination of $c i s-\left(\mathrm{Et}_{3} \mathrm{P}\right)_{2} \mathrm{Pt}^{\mathrm{II}}$ corners with tetratopic $\mathrm{M}^{\prime} \mathrm{TPP}$ ligands and ditopic XDC linkers yield tetragonal 3D prisms containing two cofacial M'TPP ligands and four XDC linkers held together by eight Pt(II) corners ${ }^{30,33,34}$ or 2D bow ties containing a M'TPP core and two parallel XDC linkers connected by four shared Pt(II) corners, herein, we employed four different XDC ligands (HDC, BPDC, BDC, and NDC) having different lengths, rigidity, and electron density. For consistency, we have adopted the exact same self-assembly conditions reported in the literature, ${ }^{30,33,34}$ i.e., a 4:1:2 stoichiometry of cis-(Et 3 P) $2 \mathrm{Pt}(\mathrm{TfO}), \mathrm{M}^{\prime} \mathrm{TPP}$, and XDC, solvent mixtures $\left(1: 1: 1 \mathrm{CH}_{2} \mathrm{Cl}_{2} / \mathrm{MeCN} / \mathrm{MeNO}_{2}\right.$ or 4:1 $\left.\mathrm{Me}_{2} \mathrm{CO} / \mathrm{H}_{2} \mathrm{O}\right)$ that adequately solubilized all components, temperature $\left(\sim 60^{\circ} \mathrm{C}\right)$, and reaction time $(\sim 18$ h) that presumably led to the prism formation. Although previous reports have claimed that tricomponent self-assembly of $\mathrm{HDC}$ and BDC linkers with M'TPP ligand and $\left(\mathrm{Et}_{3} \mathrm{P}\right)_{2} \mathrm{Pt}^{\mathrm{II}}$ corners yielded 3D prisms, ${ }^{30,33,34,39}$ our comprehensive 1D and 2D NMR, ESI-MS, single-crystal X-ray, and computational studies unequivocally demonstrated that regardless of their lengths and rigidity, all four XDC linkers exclusively afforded bow tie architectures BT1-BT4 containing ZnTPP and BT1'-BT4' containing $\mathrm{H}_{2} \mathrm{TPP}$ cores (Scheme 1, Figure 1) instead of any 3D prisms. 

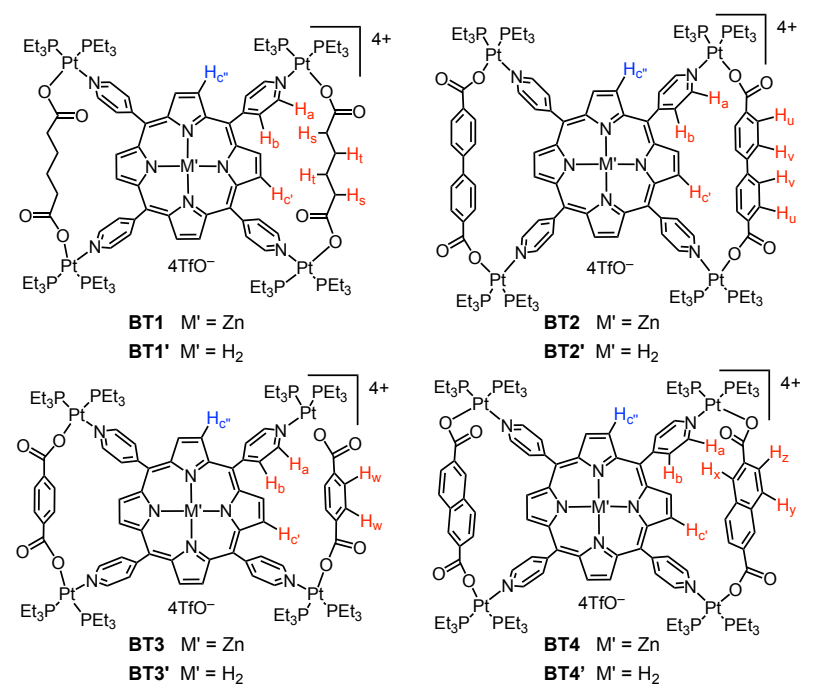

Fig. 1. The chemical structures of bow tie complexes.

${ }^{31}$ P NMR Spectroscopy. Simultaneous coordination of a pyridyl group of M'TPP and a carboxylate group of XDC with cis- $\left(\mathrm{Et}_{3} \mathrm{P}\right)_{2} \mathrm{Pt}^{\mathrm{II}}$ was evident from the ${ }^{31} \mathrm{P}$ NMR spectra of the resulting SCCs (Fig. 2 and S1). While cis-( $\left.\mathrm{Et}_{3} \mathrm{P}\right)_{2} \mathrm{Pt}(\mathrm{TfO})_{2}$ displayed a characteristic singlet at $11.14 \mathrm{ppm}$ indicating that both $\mathrm{Pt}(\mathrm{II})-$ coordinated P atoms were chemically equivalent, the resulting BT1-BT4 and BT1'-BT4' complexes displayed two distinct doublets - one at ca. 0-2 ppm that corresponded to the P-nucleus trans- to the pyridyl-N atom and another at 6-7 ppm $\left({ }^{2} J_{\mathrm{P}-\mathrm{P}} \approx 20-21 \mathrm{~Hz}\right)$ corresponding to the P-nucleus trans- to the carboxylate $\mathrm{O}$-atom-indicating that the two ancillary $\mathrm{Et}_{3} \mathrm{P}$ ligands were no longer chemically equivalent. ${ }^{30,33,34}$ The fact that no other ${ }^{31} \mathrm{P}$ NMR signal was observed further confirmed exclusively heteroleptic coordination of two different ligands with the Pt(II) corners and ruled out the formation of any homoleptic complex. However, the ${ }^{31} \mathrm{P}$ NMR spectra shed little light on the actual structures and compositions of the resulting tricomponent SCCs, i.e., whether they were 3D prisms or 2D bow ties, as both structures would feature the same heteroleptic $c i s-\left(\mathrm{Et}_{3} \mathrm{P}\right){ }_{2} \mathrm{P}^{\mathrm{II}}(\mathrm{N}, \mathrm{O})$ corners.

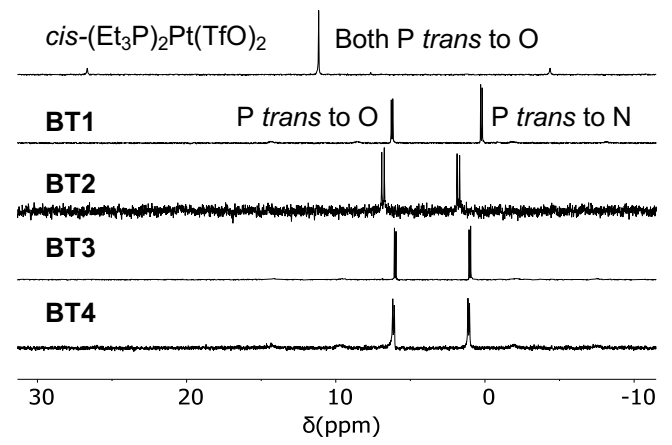

Fig. 2. Partial ${ }^{31} \mathrm{P}$ NMR spectra $\left(122 \mathrm{MHz}\right.$, acetone- $\left.d_{6}\right)$ of $c i s-\left(\mathrm{Et}_{3} \mathrm{P}\right)_{2} \mathrm{Pt}(\mathrm{TfO})$, BT1, BT2, BT3, and BT4. 
${ }^{1}$ H NMR Spectroscopy. The ${ }^{1}$ H NMR spectra of the resulting SCCs (Fig. 3, S2, and S3) presented the first telltale signs of their bow tie structures and ruled out tetragonal prism formation. In comparison to $D_{4 \mathrm{~h}^{-}}$ symmetric free ZnTPP ligand, which displayed two doublets at 8.58 and $7.95 \mathrm{ppm}$ corresponding to its $\mathrm{H}_{\mathrm{a}}$ and $\mathrm{H}_{\mathrm{b}}$ pyridyl protons ( 8 each), respectively, and a sharp singlet at $8.61 \mathrm{ppm}$ for all eight chemically equivalent $\mathrm{H}_{\mathrm{c}}$ pyrrole protons (Fig. 3), BT1-BT4 complexes not only displayed significant downfield shift of $\mathrm{H}_{\mathrm{a}}$ and $\mathrm{H}_{\mathrm{b}}$ pyridyl protons due to $\mathrm{Pt}(\mathrm{II})$-coordination, but most tellingly, two distinct singlets (1:1 intensity) for pyrrole protons $\left(\mathrm{H}_{\mathrm{c}^{\prime}}\right.$ and $\left.\mathrm{H}_{\mathrm{c}^{\prime \prime}}\right)$ indicating that the pyrrole rings of ZnTPP were no longer chemically equivalent. The same phenomenon was observed for $\mathrm{H}_{2}$ TPP-based BT1'-BT4' complexes (Fig. S2). Different NMR chemical shifts of pyrrole protons of M'TPP ligands are the telltale signs of bow tie structures, in which the pyrrole rings were located in two different environments.

The singlets peaks corresponding to four $\mathrm{H}_{\mathrm{c}^{\prime}}$ pyrrole protons of BT1-BT4 complexes appeared at $8.38,7.73,7.13$, and $6.79 \mathrm{ppm}$, respectively, which were significantly up-field shifted from the $\mathrm{H}_{\mathrm{c}}$ signal (8.61 ppm) of free ZnTPP, while the singlets corresponding to four $\mathrm{H}_{\mathrm{c}^{\prime \prime}}$ pyrrole protons appeared at 9.18, $8.52,9.16$, and $8.86 \mathrm{ppm}$, respectively. Thus, the up-field shifts of $\mathrm{H}_{\mathrm{c}^{\prime}}$ signals were directly correlated to the increasing electron cloud, i.e., the shielding effect of XDC linkers ( $\mathrm{HDC}<\mathrm{BPDC}<\mathrm{BDC}<\mathrm{NDC}$ ), suggesting that these pyrrole protons were located inside the isosceles triangles formed by two parallel XDC linkers, whereas the $\mathrm{H}_{\mathrm{c}^{\prime \prime}}$ pyrrole protons were not. The aliphatic HDC linkers in BT1 exerted the least shielding effect, causing the smallest up-field shift of the enclosed $\mathrm{H}_{\mathrm{c}^{\prime}}$ pyrrole protons located across the bay, followed by the BPDC linkers having two twisted phenyl rings that were not properly aligned with the enclosed $\mathrm{H}_{\mathrm{c}^{\prime}}$ pyrrole protons of BT2, as seen from its single-crystal structure (vide infra). Having the largest $\pi$-cloud and maximum shielding effect among four XDC linkers employed here, the NDC linkers in BT4 caused the largest up-field shift of enclosed $\mathrm{H}_{\mathrm{c}^{\prime}}$ protons, followed by the BDC linkers in BT3. Although the exposed $\mathrm{H}_{\mathrm{c}^{\prime \prime}}$ pyrrole protons were not shielded by distant XDC linkers, their chemical shifts were affected by the length of the XDC linkers, which controlled their distances from the adjacent pyridyl rings of ZnTPP. This was further evident from their crystal structures (vide infra) and certain structural parameters summarized in Table 1. For instance, the shorter HDC and BDC linkers ( $l \approx 7 \AA$ ) placed the bridged $\operatorname{Pt}($ II) corners closer to each other, which in turn, pulled the pyridyl rings of ZnTPP ligand away from the exposed $\mathrm{H}_{\mathrm{c}^{\prime \prime}}$ pyrrole protons of BT1 and BT3 complexes. This phenomenon reduced the shielding effect of pyridyl rings on $\mathrm{H}_{\mathrm{c}^{\prime \prime}}$ pyrrole protons in BT1 and BT3, causing them to appear at more downfield positions (ca. 9.2 $\mathrm{ppm})$ than the $\mathrm{H}_{\mathrm{c}}$ protons of free ZnTPP ligand. On the other hand, the longest BPDC linkers $\left(l_{\mathrm{BPDC}}=11.2\right.$ $\AA$ ) in BT2 held the bridged Pt(II) corners farther away from each other, which in turn, pushed the pyridyl rings of ZnTPP closer to exposed $\mathrm{H}_{\mathrm{c}^{\prime \prime}}$ pyrrole protons making them more shielded and up-field shifted than 
the $\mathrm{H}_{\mathrm{c}}$ protons of free ZnTPP. Having an intermediate length, NDC linkers ( $\left.l_{\mathrm{NDC}}=9.2 \AA\right)$ in BT4 pulled the pyridyl rings of ZnTPP slightly away from exposed $\mathrm{H}_{\mathrm{c}^{\prime \prime}}$ protons, causing a slight downfield shift. The exact same trends were observed for $\mathrm{H}_{2}$ TPP-based BT1'-BT4' complexes (Fig. S2).

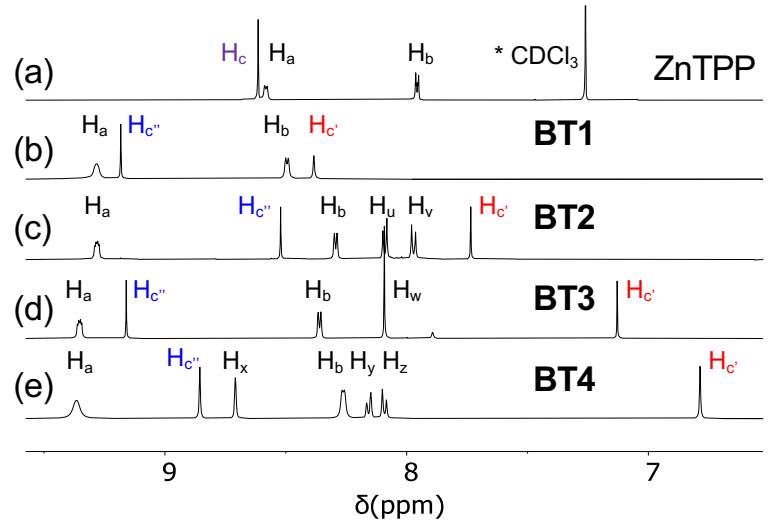

Fig. 3. Partial ${ }^{1} \mathrm{H}$ NMR spectra (500 MHz) of (a) free ZnTPP ligand, (b) BT1, (c) BT2, (d) BT3, and (e) BT4. The enclosed $\mathrm{H}_{\mathrm{c}^{\prime}}$ pyrrole protons (highlighted in red) located inside the isosceles triangles of bow tie structures were shielded proportionately by adjacent XDC linkers, whereas the exposed $\mathrm{H}_{\mathrm{c}^{\prime \prime}}$ pyrrole protons (highlighted in blue) were not.

Thus, the splitting of pyrrole protons of M'TPP ligands into two chemically nonequivalent and noncoupled $\mathrm{H}_{\mathrm{c}^{\prime}}$ and $\mathrm{H}_{\mathrm{c}^{\prime \prime}}$ protons in the tricomponent $\mathrm{SCC}$ and variable shielding of the former by XDC linkers were the telltale signs of bow tie complexes where two opposite pyrrole rings bearing four $\mathrm{H}_{\mathrm{c}^{\prime}}$ protons were located inside the isosceles triangles formed by two parallel XDC linkers while the other two pyrrole rings bearing four $\mathrm{H}_{\mathrm{c}^{\prime \prime}}$ protons remained exposed. It is worth noting all previously reported M'TPPbased tricomponent SCCs, including those containing HDC and BDC ligands, ${ }^{32,33}$ essentially displayed the same ${ }^{1} \mathrm{H}$ NMR characteristics as those displayed by BT1, BT1', BT3, and BT3', i.e., two distinct singlets for $\mathrm{H}_{\mathrm{c}^{\prime}}$ and $\mathrm{H}_{\mathrm{c}^{\prime \prime}}$ pyrrole protons that indicated their bow tie structures. However, these characteristic NMR signals of bow tie structures were overlooked previously, and the complexes were thought to be tetragonal prisms primarily based on their ESI-MS data (vide infra). ${ }^{30,33,34,56}$ If these tricomponent SCCs were indeed tetragonal prisms having two cofacial M'TPP planes connected by four XDC linkers via heteroleptic $\left(\mathrm{Et}_{3} \mathrm{P}\right)_{2} \mathrm{Pt}^{\mathrm{II}}(\mathrm{N}, \mathrm{O})$ corners, then all sixteen pyrrole protons of $\mathrm{M}^{\prime} \mathrm{TPP}$ faces should have remained chemically equivalent and displayed one singlet peak, as observed in actual porphyrin-based prisms, ${ }^{47-49,53,55}$ instead of splitting into two chemically non-equivalent $\mathrm{H}_{\mathrm{c}^{\prime}}$ and $\mathrm{H}_{\mathrm{c}^{\prime \prime}}$ protons that showed two distinct singlets. However, that was not observed for any of the Pt(II)/M'TPP/XDC-based tricomponent SCCs presented either here or in the literature, ${ }^{30,33,34,56}$ which ruled out any prism formation. 
${ }^{1}{ }^{1}-{ }^{1} H$ COSY NMR Spectroscopy. The COSY NMR spectra of these M'TTP-based tricomponent SCCs (Fig. S4) provided further insights into their actual structures by revealing the coupling between the adjacent ( $\alpha$ - and $\beta$-) protons. Conspicuously missing from the COSY NMR spectra of all these SCCs were any $\alpha / \beta$ coupling between the $\mathrm{H}_{\mathrm{c}^{\prime}}$ and $\mathrm{H}_{\mathrm{c}^{\prime \prime}}$ protons of M'TPP ligand, which further indicated that these two chemically non-equivalent protons did not belong to the same pyrrole ring but to two separate pyrrole rings located in different environments. This scenario was possible only in bow tie structures where two opposite pyrrole rings carrying the $\mathrm{H}_{\mathrm{c}^{\prime}}$ protons were located inside the triangles, whereas the other two pyrrole rings bearing $\mathrm{H}_{\mathrm{c}^{\prime \prime}}$ protons remained exposed. If these tricomponent SCCs were indeed tetragonal prisms containing two cofacial M'TPP panels linked by four XDC linkers, then either all the pyrrole protons of M'TPP should have remained chemically equivalent instead of splitting into distinct $\mathrm{H}_{\mathrm{c}^{\prime}}$ and $\mathrm{H}_{\mathrm{c}^{\prime \prime}}$ protons, or each pyrrole ring would have carried one $\mathrm{H}_{\mathrm{c}^{\prime}}$ and one $\mathrm{H}_{\mathrm{c}^{\prime \prime}}$ protons that would have allowed $\alpha / \beta$-coupling. The absence of such couplings ruled out the prism formation.

ROESY NMR Spectroscopy. Another powerful evidence of bow tie complex formation was found in the ROESY NMR spectra (Fig. 4 and S5), which revealed long-range coupling between the enclosed $\mathrm{H}_{\mathrm{c}^{\prime}}$ pyrrole protons of M'TPP and the XDC protons located across the bay. For example, the enclosed $\mathrm{H}_{\mathrm{c}^{\prime}}$ pyrrole protons were coupled with (i) the $\mathrm{H}_{\mathrm{t}}$ protons of HDC in BT1 and BT1', (ii) the $\mathrm{H}_{\mathrm{u}}$ and $\mathrm{H}_{\mathrm{v}}$ protons of BPDC in BT2 and BT2', (iii) the $\mathrm{H}_{\mathrm{w}}$ protons of BDC in BT3 and BT3', and (iv) the $\mathrm{H}_{\mathrm{x}}, \mathrm{H}_{\mathrm{y}}$, and $\mathrm{H}_{\mathrm{z}}$ protons of NDC in BT4 and BT4', indicating that the enclosed pyrrole rings were located in close proximity of the XDC linkers. In addition, the enclosed $\mathrm{H}_{\mathrm{c}^{\prime}}$ protons were also coupled to adjacent $\mathrm{H}_{\mathrm{b}}$ pyridyl protons of M'TPP ligands. However, no such ROE-coupling between the exposed $\mathrm{H}_{\mathrm{c}^{\prime \prime}}$ pyrrole protons and the remote XDC protons were observed (the $\mathrm{H}_{\mathrm{c}^{\prime \prime}}$ protons were only coupled to $\mathrm{H}_{\mathrm{b}}$ protons of the adjacent pyridyl ring in some cases), further verifying that the enclosed $\mathrm{H}_{\mathrm{c}^{\prime}}$ and exposed $\mathrm{H}_{\mathrm{c}^{\prime \prime}}$ pyrrole protons were located in two different chemical environments. This scenario would be only possible in bow tie structures, not in prisms. 

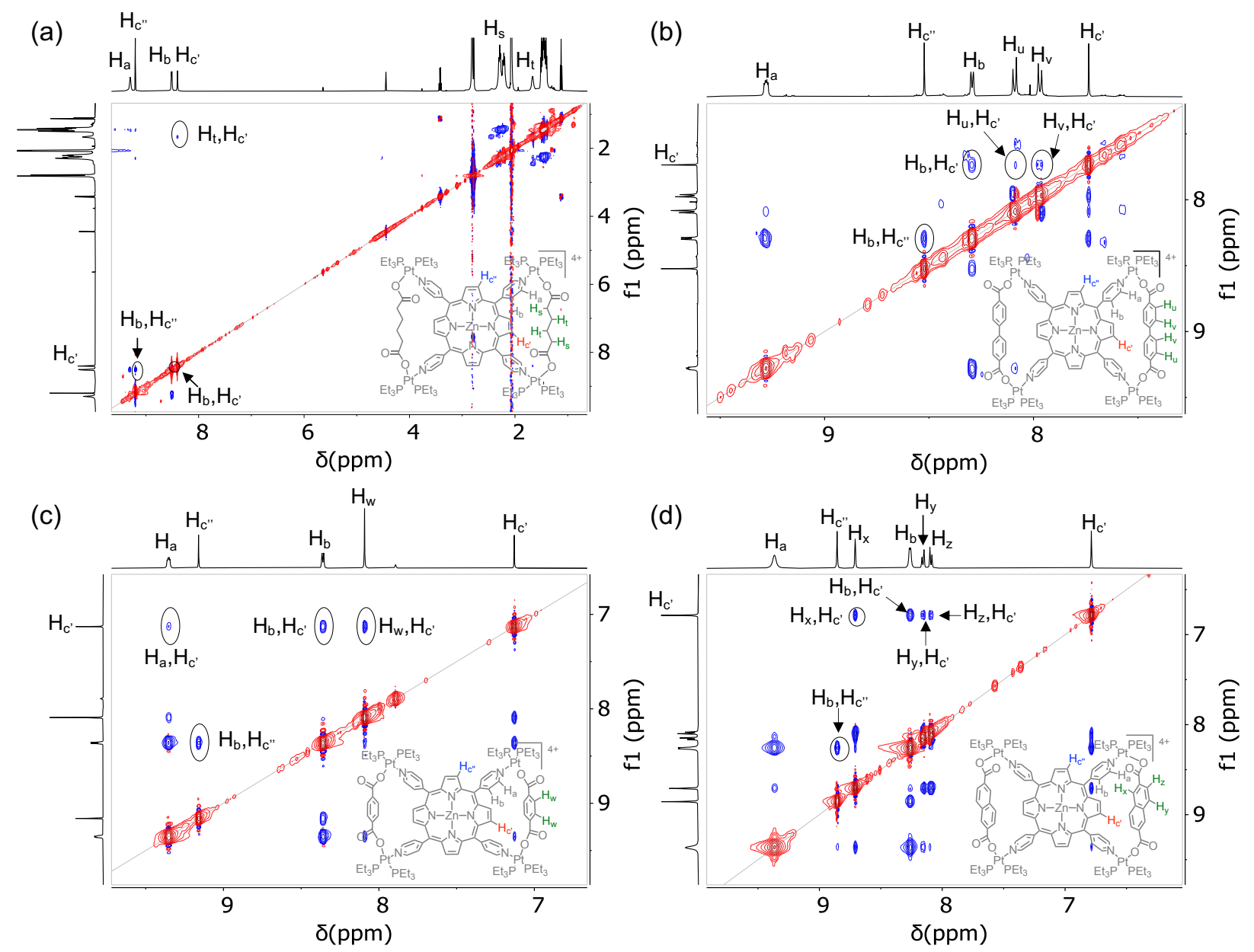

Fig. 4. Partial ${ }^{1} \mathrm{H}-{ }^{1} \mathrm{H}$ ROESY NMR spectra (500 MHz, acetone- $d_{6}$ ) of (a) BT1, (b) BT2, (c) BT3, and (d) BT4 show that the enclosed $\mathrm{H}_{\mathrm{c}^{\prime}}$ pyrrole protons of these bow tie complexes located inside the isosceles triangles are through-space coupled with the protons of adjacent XDC linkers but the exposed $\mathrm{H}_{\mathrm{c}^{\prime \prime}}$ pyrrole protons are not coupled with the distant XDC protons.

ESI-MS Analysis. The ESI-MS analysis revealed (Fig. S6) the characteristic $m / z$ peaks of $[\mathrm{M}-2 \mathrm{TfO}]^{2+}$ species of bow tie complexes. The ZnTPP-based BT1, BT2, BT3, and BT4 and $\mathrm{H}_{2}$ TPP-based BT2', BT3', and BT4' displayed the respective $[\mathrm{M}-2 \mathrm{TfO}]^{2+}$ peaks at $\mathrm{m} / z=1497.09,1593.58,1517.01,1567.05$, $1561.50,1485.52$, and 1535.60, but no peak associated with tetragonal prisms although of these SCCs were assembled under the same reported conditions that arguably yielded the so-called prisms. ${ }^{33}$ Although the $m / z$ peaks of $\left[\mathrm{M}-\mathrm{nX}^{-}\right]^{\mathrm{n}+}$ species $\left(\mathrm{X}^{-}=\mathrm{TfO}^{-}\right.$or $\mathrm{PF}_{6}^{-}, \mathrm{n}=3$ or 5$)$ of the purported prisms were observed previously, ${ }^{30,33}$ a closer look at the previously reported ${ }^{30}$ ESI-MS profile of a tricomponent SCC featuring $\left(\mathrm{Et}_{3} \mathrm{P}\right)_{2} \mathrm{Pt}^{\mathrm{II}}, \mathrm{H}_{2} \mathrm{TPP}$, and BDC revealed a prominent $\mathrm{m} / \mathrm{z}$ peak at $1481.38(\sim 100 \%$ relative intensity, $4-5$ times higher than any other peaks), which actually represented the $\left[\mathrm{M}-2 \mathrm{PF}_{6}{ }^{-}\right]^{2+}$ species of bow tie complex 
$\left[\left\{\left(\mathrm{Et}_{3} \mathrm{P}\right)_{2} \mathrm{Pt}\right\}_{4}\left(\mathrm{H}_{2} \mathrm{TPP}\right)(\mathrm{BDC})_{2}\right]^{4+} \bullet 4\left(\mathrm{PF}_{6}{ }^{-}\right)$but was overlooked previously. Since none of the previously reported $\mathrm{M}^{\prime}$ TPP-based tricomponent SCCs displayed the expected ${ }^{1} \mathrm{H}$ NMR spectra that could have supported the proposed prism formation (vide supra), ${ }^{30,33,34,56,57}$ and our extensive 2D NMR and ESI-MS data discussed above as well as the single-crystal structures presented below unequivocally demonstrated the formation of bow tie complexes instead of any prisms, it is plausible that the $m / z$ peaks that were previously ascribed to $8: 2: 4\left[\left\{\left(\mathrm{Et}_{3} \mathrm{P}\right)_{2} \mathrm{Pt}\right\}_{8}\left(\mathrm{M}^{\prime} \mathrm{TPP}\right)_{2}(\mathrm{XDC})_{4}\right]^{8+} \bullet 8\left(\mathrm{X}^{-}\right)$prisms, were actually associated with the dimers of $4: 1: 2\left[\left\{\left(\mathrm{Et}_{3} \mathrm{P}\right)_{2} \mathrm{Pt}\right\}_{4}\left(\mathrm{M}^{\prime} \mathrm{TPP}\right)(\mathrm{XDC})_{2}\right]^{4+} \bullet 4\left(\mathrm{X}^{-}\right)$bow tie complexes (after loss of some counterions) instead of the proposed prisms. Alternatively, the bow tie complexes could have reorganized into prisms under certain electrospray ionization conditions, giving a false impression about the proposed prisms formation, which was not otherwise supported by any other experimental data.

Single-Crystal Structures of Bow Tie Complexes. The single-crystal structures these tricomponent SCCs presented the most direct and conclusive evidence of their bow tie structures consisting of a M'TPP core and two parallel XDC linkers held together by four heteroleptic $\left(\operatorname{Et}_{3} \mathrm{P}\right)_{2} \mathrm{Pt}(\mathrm{N}, \mathrm{O})$ corners. Notably, this was the first time the crystal structures of any M'TPP-based tricomponent SCCs could be determined. The crystals were obtained from their NMR solutions (acetone- $d_{6}$ ) via either slow evaporation or vapor diffusion of $\mathrm{CH}_{2} \mathrm{Cl}_{2}$ or $\mathrm{Et}_{2} \mathrm{O}$, assuring that the solid-state crystal structures and solution NMR data belonged to the same materials. The bow tie complexes based on rigid aromatic BPDC, BDC, and NDC linkers crystallized easily, but those containing flexible aliphatic HDC linkers did not. The structural features of all bow tie complexes (Table 1) were fully consistent with their respective NMR and ESI-MS data, confirming that the same species were present both in solutions and solid crystals. The crystal structures of these bow tie complexes also helped explain why the enclosed $\mathrm{H}_{\mathrm{c}^{\prime}}$ pyrrole proton signals were shifted up-field and ROE-coupled with the XDC protons located across the bay, but the exposed $\mathrm{H}_{\mathrm{c}^{\prime \prime}}$ pyrrole protons were not. 

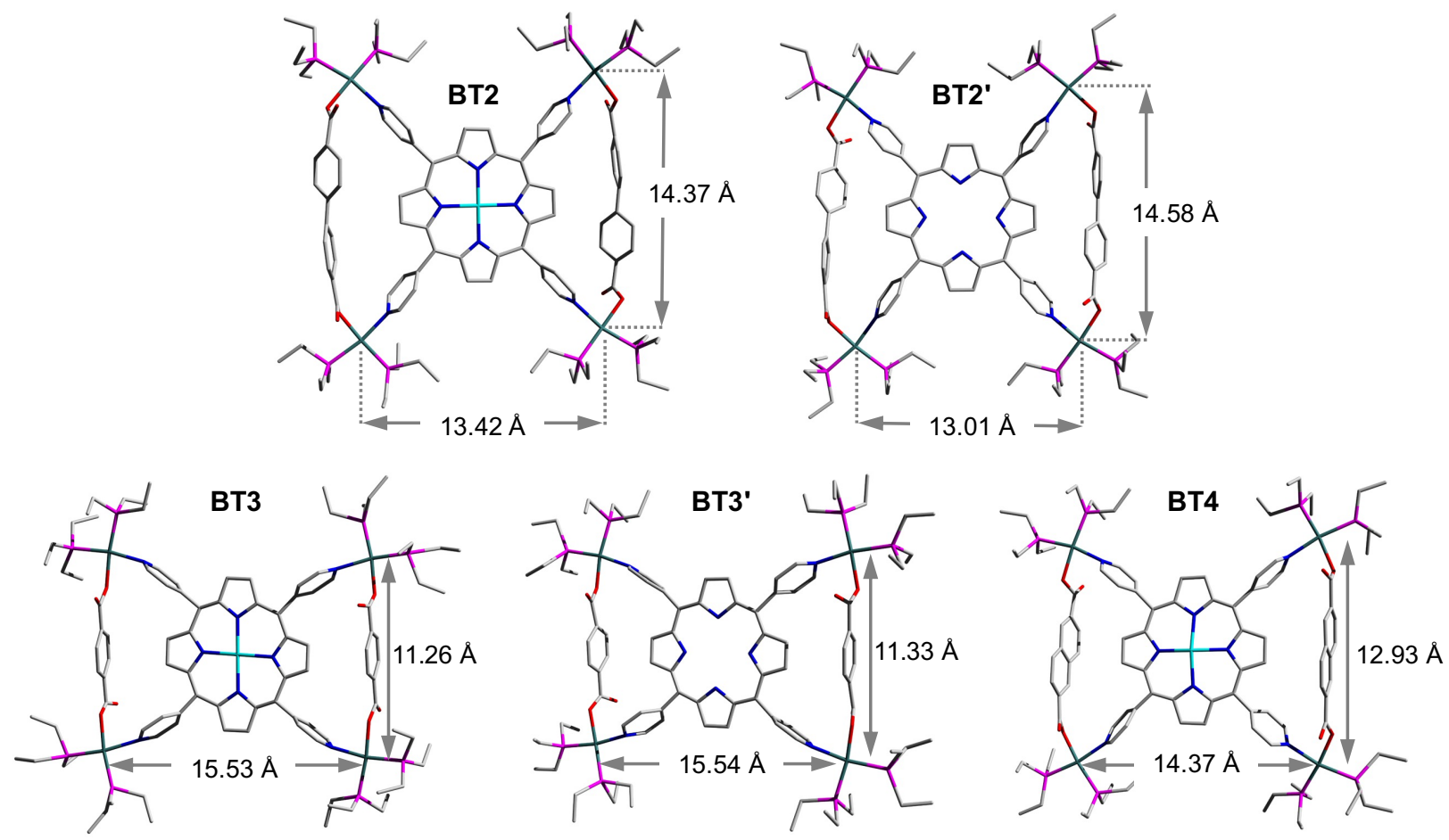

Fig. 5. Single-crystal structures of BT2, BT2', BT3, BT3' and BT4 bow tie complexes. Atom legends: green: Pt, cyan: Zn, pink: $\mathrm{P}$, red: $\mathrm{O}$, blue: $\mathrm{N}$, grey: $\mathrm{C}$. The $\mathrm{H}$-atoms and $\mathrm{TfO}^{-}$anions were omitted for clarity.

Table 1. Key structural parameters of bow tie complexes obtained from their single-crystal structures. The parameters obtained from the calculated structures are labeled with asterisks $(*)$.

\begin{tabular}{|c|c|c|c|c|c|c|}
\hline & BT1 calc. * & BT2 & BT2' $^{\prime}$ & BT3 (calc.*) & BT3' (calc. *) & BT4 \\
\hline Space Group & - & $P \overline{1}$ & $\mathrm{C} 2 / \mathrm{c}$ & $\mathrm{C} 2 / \mathrm{c}$ & $14_{1} / \mathrm{a}$ & $P 2_{1} / \mathrm{c}$ \\
\hline$d_{\mathrm{Pt}-\mathrm{Pt} / \mathrm{int}}(\AA)$ & $11.55^{*}$ & 14.37 & 14.58 & $11.26\left(11.33^{*}\right)$ & $11.33\left(11.33^{\star}\right)$ & 12.93 \\
\hline$d_{\text {Pt-Pt/ext }}(\AA)$ & $15.41^{*}$ & 13.42 & 13.01 & $15.53\left(15.59^{*}\right)$ & $15.54\left(15.56^{\star}\right)$ & 14.37 \\
\hline$d_{N-N / i n t}(\AA)$ & $10.19^{*}$ & 11.38 & 11.52 & $10.09\left(10.12^{*}\right)$ & $10.07\left(10.20^{*}\right)$ & 10.83 \\
\hline$d_{\mathrm{N}-\mathrm{N} / \mathrm{ext}}(\AA)$ & $11.63^{*}$ & 10.37 & 10.18 & $11.39\left(11.69^{*}\right)$ & $11.61\left(11.68^{\star}\right)$ & 10.80 \\
\hline$d_{\mathrm{Hc}^{\prime} \text { XDC-center }}(\AA)$ & $2.84^{*}$ & 3.37 & 3.11 & $3.18\left(3.50^{*}\right)$ & $3.05\left(3.44^{*}\right)$ & 2.95 \\
\hline$d_{\text {Hc'-Pyridine-center }}(\AA)$ & $2.96^{*}$ & 3.41 & 3.51 & $3.02\left(2.98^{*}\right)$ & $2.96\left(3.01^{*}\right)$ & 3.19 \\
\hline$d_{H C^{\prime \prime}-\text { Pyridine-center }}(\AA)$ & $3.37^{*}$ & 3.08 & 3.00 & $3.41\left(3.47^{*}\right)$ & $3.47\left(3.41^{*}\right)$ & 3.26 \\
\hline$\angle \mathrm{N}-\mathrm{Pt}-\mathrm{O}\left({ }^{\circ}\right)$ & $96^{*}, 98^{*}$ & 82,85 & 82,83 & $78,83\left(93^{*}\right)$ & $80,83\left(93^{*}\right)$ & 82,82 \\
\hline$\angle\left(\mathrm{N}_{\mathrm{Py}}-\text { Center- } \mathrm{N}_{\mathrm{Py}}\right)_{\text {int }}\left({ }^{\circ}\right)$ & $82^{*}$ & 95 & 97 & $83\left(81^{*}\right)$ & $82\left(82^{*}\right)$ & 88 \\
\hline$\angle\left(\mathrm{N}_{\mathrm{Py}}-\text { Center- } \mathrm{N}_{\mathrm{Py}}\right)_{\text {ext }}\left({ }^{\circ}\right)$ & $98^{*}$ & 85 & 83 & $97\left(99^{*}\right)$ & $98\left(98^{*}\right)$ & 89 \\
\hline$\theta_{\text {Porphyrin/Pyridyl-dh }}\left({ }^{\circ}\right)$ & $82^{*}, 83^{*}$ & 76,77 & 64,73 & $86,88\left(84^{*}\right)$ & $76,80\left(85^{\star}\right)$ & 65,76 \\
\hline$\theta_{\text {Pyrrole/XDC-dh }}\left({ }^{\circ}\right)$ & - & - & - & $80\left(90^{*}\right)$ & $85\left(90^{*}\right)$ & 87 \\
\hline
\end{tabular}

The bow tie $(\bowtie)$-shaped BT2 and BT2' complexes (Fig. 5: $\left[\left\{\left(\mathrm{Et}_{3} \mathrm{P}\right)_{2} \mathrm{Pt}\right\}_{4}\left(\mathrm{M}^{\prime} \mathrm{TPP}\right)(\mathrm{BPDC})_{2}\right]^{4+}, \mathrm{M}^{\prime}=$ $\mathrm{Zn}$ or $\mathrm{H}_{2}$ ) crystallized in $P \overline{1}$ and $C 2 / \mathrm{c}$ space groups, respectively. The $\angle \mathrm{N}-\mathrm{Pt}-\mathrm{O}$ angles of slightly distorted square-planar $\mathrm{Pt}(\mathrm{II})$ corners ranged between ca. $82-85^{\circ}$ (two diagonally opposite angles were the same). In BT2 and BT2', the distances between two BPDC-bridged Pt(II) corners ( $\left.d_{\mathrm{Pt}-\mathrm{Pt} / \text { int }}\right)$ were ca. 14.5 and $14.6 \AA$, 
respectively, whereas those between two adjacent Pt(II) corners not bridged by BPDC $\left(d_{\mathrm{Pt} \text {-Pt/ext }}\right)$ were 13.4 and 13.0 $\AA$, respectively. This happened because the long BPDC linker $\left(l_{\mathrm{BPDC}}=11.2 \AA\right)^{58}$ positioned the two bridged $\mathrm{Pt}(\mathrm{II})$ corners farther away from each other, which in turn shortened $d_{\mathrm{Pt}-\mathrm{Pt} / \mathrm{ext}}$. Consequently, the distances between the two adjacent pyridyl-N atoms coordinated to two BPDC-bridged Pt(II) corners, i.e., the pyridyl-N atoms that belonged to the same isosceles triangle, were also noticeably longer $\left(d_{\mathrm{N}-\mathrm{N} / \mathrm{int}} \approx 11.4\right.$ and $\AA$ ) than the distance between two adjacent pyridyl-N atoms that were not part of the same triangle $\left(d_{\mathrm{N}-}\right.$ $\mathrm{N} / \mathrm{ext} \approx 10.4 \AA$ ). These $\mathrm{N}-\mathrm{N}$ distances in BT2 and BT2' deviated from the uniform distance between two adjacent pyridyl-N atoms of free $\mathrm{M}^{\prime} \mathrm{TPP}$ ligands $\left(d_{\mathrm{N}-\mathrm{N} / \text { free }} \approx 10.9 \AA\right) .{ }^{59,60}$ Furthermore, in BT2, the angles of projection between two adjacent pyridyl rings that belonged to the same triangle $\left(\angle\left(\mathrm{N}_{\mathrm{Py}}-\text { center- } \mathrm{N}_{\mathrm{Py}}\right)_{\text {int }}\right)$ expanded to $95^{\circ}\left(97^{\circ}\right.$ in $\left.\mathbf{B T 2}{ }^{\prime}\right)$, while the angle between two adjacent pyridyl rings that were not part to the same triangle $\left(\angle\left(\mathrm{N}_{\mathrm{Py}}-\text { center- } \mathrm{N}_{\mathrm{Py}}\right)_{\mathrm{ext}}\right)$ contracted to $85^{\circ}\left(83^{\circ}\right.$ in $\left.\mathbf{B T 2} \mathbf{2}^{\prime}\right)$. Thus, these angles deviated by $3-5^{\circ}$ from the angles of projection $\left(\sim 90^{\circ}\right)$ between the adjacent pyridyl rings of free M'TPP in order to incorporate long BPDC linkers within the isosceles triangles of bow tie structures. The dihedral angles between the porphyrin core and the pyridyl arms were $76^{\circ}$ in $\mathbf{B T 2}\left(73^{\circ}\right.$ in $\left.\mathbf{B T 2} 2^{\prime}\right)$. The enclosed pyrrole rings of M'TPP and the twisted BPDC core (torsion angle between two phenyl rings $\approx 40^{\circ}$ ) located across the bay were not coplanar but formed large dihedral angles. The average distances from the enclosed $\mathrm{H}_{\mathrm{c}^{\prime}}$ pyrrole protons located inside the triangles to the center of the closest phenyl ring of BPDC linker $\left(d_{\mathrm{Hc}^{\prime}-\mathrm{XDC}}\right)$ was ca. $3.4 \AA$ in BT2 $(3.1 \AA$ in BT2' $)$ and to the center of the nearest pyridyl ring ( $\left.d_{\mathrm{Hc}^{\prime}-\text { Pyridine-center }}\right)$ was $3.4 \AA$ in

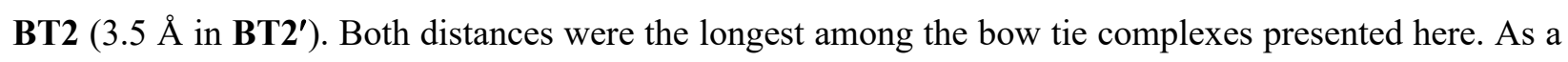
result, the enclosed $\mathrm{H}_{\mathrm{c}^{\prime}}$ pyrrole protons of BT2 and BT2' were less shielded and less up-field shifted than those of BDC-and NDC-based bow tie complexes (Fig. 3). Furthermore, the long BPDC linker pushed the pyridyl rings of M'TPP closer to the exposed $\mathrm{H}_{\mathrm{c}^{\prime \prime}}$ pyrrole protons $\left(d_{\mathrm{Hc}^{\prime \prime}-\text { Pyridine-center }} \sim 3.1 \AA\right)$ causing a modest shielding and up-field chemical shift of these protons with respect to the $\mathrm{H}_{\mathrm{c}}$ signal of free $\mathrm{M}^{\prime} \mathrm{TPP}$ ligands. The other bow tie complexes having shorter XDC ligands did not display any up-field shift of the exposed $\mathrm{H}_{\mathrm{c}^{\prime \prime}}$ signals because the shorter linkers pulled the adjacent pyridyl rings away from the exposed $\mathrm{H}_{\mathrm{c}^{\prime \prime}}$ pyrrole protons and closer to the enclosed $\mathrm{H}_{\mathrm{c}^{\prime}}$ pyrrole protons.

Although the entire single-crystal structures of BT2 and BT2' complexes, including their ancillary $\mathrm{Et}_{3} \mathrm{P}$ ligands on the Pt(II) corners, were well-resolved, only the basic bow tie skeletons of BT3, BT3', and BT4 complexes consisting of the M'TPP core, two parallel BDC and NDC linkers, and four Pt(II) corners were fully resolved, but the fluxional $\mathrm{CH}_{3} \mathrm{CH}_{2}$-groups and $\mathrm{TfO}^{-}$anions were not, which caused large $R$ values. Nevertheless, since the ancillary ligands and counterions were not integral parts of the bow tie 
structures, the poor resolution of these highly disordered components had little effect on key structural features that influenced their respective NMR spectra.

The BDC-based bow tie complexes BT3 and BT3' (Fig. 5: $\left[\left\{\left(\mathrm{Et}_{3} \mathrm{P}\right)_{2} \mathrm{Pt}\right\}_{4}\left(\mathrm{M}^{\prime} \mathrm{TPP}\right)(\mathrm{BDC})_{2}\right]^{4+}, \mathrm{M}^{\prime}=$ $\mathrm{Zn}$ or $\mathrm{H}_{2}$ ) crystallized in $C 2 / \mathrm{c}$ and $I 4_{1} /$ a space groups, respectively. The $\angle \mathrm{N}-\mathrm{Pt}-\mathrm{O}$ angles at distorted squareplanar $\mathrm{Pt}(\mathrm{II})$ corners ranged between ca. $78-83^{\circ}$. The distances between two adjacent $\mathrm{Pt}(\mathrm{II})$ corners bridged by short BDC linkers $\left(l_{\mathrm{BDC}}=6.9 \AA\right)^{58}$ were ca. $11.3 \AA\left(d_{\mathrm{Pt}-\mathrm{Pt} / \text { int }}\right)$, whereas the distances between two adjacent $\mathrm{Pt}(\mathrm{II})$ corners not bridged by BDC ( $\left.d_{\mathrm{Pt}-\mathrm{Pt} / \mathrm{ext}}\right)$ were ca. $15.5 \AA$. Thus, the short BDC linkers placed the two bridged Pt(II) corners closer to each other while increasing the distances between the two non-bridged Pt(II) corners. Consequently, the distances between the pyridyl-N atoms that belonged to the same triangle were also shorter $\left(d_{\mathrm{N}-\mathrm{N} / \text { int }} \approx 10.1 \AA\right)$ than those between two pyridyl-N atoms that were not part of the same triangle $\left(d_{\mathrm{N}-\mathrm{N} / \mathrm{ext}} \approx 11.5 \AA\right)$. Consequently, the projection angles between two adjacent pyridyl rings belonging to the same triangle $\left(\angle\left(\mathrm{N}_{\mathrm{Py}}-\text { center- } \mathrm{N}_{\mathrm{Py}}\right)_{\text {int }}\right)$ shrunk to ca. $82^{\circ}$, while the angles between two adjacent pyridyl rings not belonging to the same triangle $\left(\angle\left(\mathrm{N}_{\mathrm{Py}}-\text { center- }-\mathrm{N}_{\mathrm{Py}}\right)_{\mathrm{ext}}\right)$ expanded to ca. $98^{\circ}$ (ca. $8^{\circ}$ deviations from the ideal $\sim 90^{\circ}$ angle in free $\mathrm{M}^{\prime} \mathrm{TPP}$ ) in order to accommodate short BDC linkers within the triangles. The dihedral angles between the enclosed pyrrole rings of M'TPP and the BDC core located across the bay were $80-85^{\circ}$, i.e., they were almost orthogonal to each other. The enclosed $\mathrm{H}_{\mathrm{c}^{\prime}}$ pyrrole protons were projected toward the center of the $\mathrm{BDC}$ ring $\left(d_{\mathrm{Hc}^{\prime}-\mathrm{XDC}} \approx 3.1 \AA\right)$ as well as the adjacent pyridyl rings, which were pulled closer $\left(d_{\mathrm{Hc}^{\prime}-\text { Pyridine-center }} \approx 3 \AA\right)$ by the BDC linker. As a result, the $\mathrm{H}_{\mathrm{c}^{\prime}}$ pyrrole protons of BT3 and BT3' complexes were highly shielded, up-field shifted, and ROE-coupled to BDC protons (Fig. $3, \mathrm{~S} 2$ ). On the other hand, since the pyridyl rings of $\mathrm{M}^{\prime} \mathrm{TPP}$ moved away from the exposed $\mathrm{H}_{\mathrm{c}^{\prime \prime}}$ pyrrole protons $\left(d_{\mathrm{Hc}^{\prime \prime}-\text { Pyridine-center }} \approx 3.4 \AA\right.$ ), they became less shielded and shifted noticeably downfield with respect to the $\mathrm{H}_{\mathrm{c}}$ signal of free M'TPP ligands.

The NDC-based bow tie complex BT4 $\left[\left\{\left(\mathrm{Et}_{3} \mathrm{P}\right)_{2} \mathrm{Pt}\right\}_{4}(\mathrm{ZnTPP})(\mathrm{NDC})_{2}\right]^{4+}$ (Fig. 5) possessed $P 2_{1} / \mathrm{c}$ space group. All four $\angle \mathrm{N}-\mathrm{Pt}-\mathrm{O}$ angles of distorted square-planar $\mathrm{Pt}(\mathrm{II})$ corners were ca. $82^{\circ}$. The distances between two adjacent NDC-bridged Pt(II) corners $\left(d_{\mathrm{Pt}-\mathrm{Pt} / \text { int }}=12.9 \AA \AA\right)$ were slightly shorter than those between two adjacent Pt(II) corners not bridged by a NDC linker $\left(d_{\mathrm{Pt}-\mathrm{Pt} / \mathrm{ext}}=14.4 \AA\right)$. However, the distances between the $\mathrm{N}$-atoms of two adjacent pyridyl rings belonging to the same triangle $\left(d_{\mathrm{N}-\mathrm{N} / \mathrm{int}}\right)$ and those between two adjacent pyridyl-N atoms that were not part of the same triangle $\left(d_{\mathrm{N}-\mathrm{N} / \mathrm{ext}}\right)$ were almost same (ca. $10.8 \AA$ ) and close to the uniform distances between two adjacent pyridyl-N atoms of free ZnTPP ligand $\left(d_{\mathrm{N}-\mathrm{N} / \text { free }} \sim 10.9 \AA\right)$. As a result, the angles between two adjacent pyridyl rings belonging to the same triangle $\left(\angle\left(\mathrm{N}_{\mathrm{Py}}-\text { Center- } \mathrm{N}_{\mathrm{Py}}\right)_{\text {int }}\right)$ and those between two adjacent pyridyl rings not belonging to the same triangle $\left(\angle\left(\mathrm{N}_{\mathrm{Py}}-\text { Center- } \mathrm{N}_{\mathrm{Py}}\right)_{\mathrm{ext}}\right)$ in $\mathbf{B T} 4$ were also close to ideal $\sim 90^{\circ}$ angle between adjacent pyridyl rings found in 
free ZnTPP ligand. Thus, the intermediate length of NDC linker $\left(l_{\mathrm{NDC}}=9.2 \AA\right)^{58}$ caused the least distortion of ZnTPP ligand in order to form the isosceles triangles. In BT4, the ZnTPP and the NDC planes were nearly orthogonal to each other (dihedral angles $=87^{\circ}$ ). The enclosed $\mathrm{H}_{\mathrm{c}^{\prime}}$ pyrrole protons located inside the triangles were projected toward the NDC core across the bay $\left(d_{\mathrm{Hc}^{\prime}-\mathrm{XDC}} \approx 3 \AA\right)$, as well as to the center of the adjacent pyridyl rings $\left(d_{\mathrm{Hc}^{\prime}-\text { Pyridine-center }} \approx 3.2 \AA\right)$. As a result, the enclosed $\mathrm{H}_{\mathrm{c}^{\prime}}$ pyrrole protons of BT4 experienced the maximum shielding effect and displayed the largest up-field NMR chemical shift. On the other hand, the distance between the exposed $\mathrm{H}_{\mathrm{c}^{\prime \prime}}$ pyrrole protons and the adjacent pyridyl rings $\left(d_{\mathrm{Hc}}\right.$-Pyridinecenter $\approx 3.3 \AA$ ) was greater than that found in BPDC-based bow ties (ca. $3 \AA$ ) but smaller than that of BDCbased bow ties (ca. $3.4 \AA$ ). As a result, the $\mathrm{H}_{\mathrm{c}^{\prime \prime}}$ protons of BT4 displayed a slight downfield chemical shift with respect to the $\mathrm{H}_{\mathrm{c}}$ signal of free ZnTPP (Fig. 3, S2).

Energy Optimized Structures. Since the crystal structures of BT1 or BT1' complexes containing flexible HDC linker were not available, we calculated their energy minimized structures using Gaussian 09 software (Fig. 6). To verify the accuracy of these calculated structures, we also calculated the energy minimized structures of BDC-based bow tie complexes, which were in good agreement with their actual crystal structures (Table 1). In BT1 and BT1' complexes, the $\angle \mathrm{N}-\mathrm{Pt}-\mathrm{O}$ angles at the distorted square-planar Pt(II) corners were ca. $96-98^{\circ}$. The two adjacent HDC-bridged Pt(II) corners $\left(d_{\text {Pt-Pt/int }}\right)$ were located ca. $11.6 \AA$ apart, whereas the two adjacent Pt(II) corners not bridged by HDC ( $\left.d_{\mathrm{Pt}-\mathrm{Pt} / \mathrm{ext}}\right)$ were located ca. $15.4 \AA$ apart. The bridged Pt-Pt distances in BT1 were comparable to those found in BT3, suggesting that HDC and BDC have similar lengths. Like BDC, the short HDC linkers also brought the two bridged Pt(II) corners closer to each other, expanding the distances between the two adjacent non-bridged Pt(II) corners. Consequently, the angles between two adjacent pyridyl rings of M'TPP that belonged to the same triangle $\left(\angle\left(\mathrm{N}_{\mathrm{Py}}-\text { center- } \mathrm{N}_{\mathrm{Py}}\right)_{\text {int }}\right)$ shrunk to $\sim 82^{\circ}$, while the angles between two adjacent pyridyl rings that were not part of the same triangle $\left(\angle\left(\mathrm{N}_{\mathrm{Py}}-\text { center- } \mathrm{N}_{\mathrm{Py}}\right)_{\text {ext }}\right)$ expanded to $\sim 98^{\circ}$ in order to accommodate short HDC linkers within the isosceles triangles of these bow tie structures. The distances from the enclosed $\mathrm{H}_{\mathrm{c}^{\prime}}$ pyrrole protons to the center of nearest pyridyl ring $\left(d_{\mathrm{Hc}^{\prime}-\text { Pyridine-center }}\right)$ were ca. $2.96 \AA$ and to the $\mathrm{H}_{\mathrm{t}}$ protons of HDC linker located across the bay were ca. $2.8 \AA$. The enclosed $H_{\mathrm{c}^{\prime}}$ protons of BT1 were least up-field shifted because they were mostly shielded by the adjacent pyridyl rings while the alkyl chain of HDC exerted little shielding effect. On the other hand, the exposed $\mathrm{H}_{\mathrm{c}^{\prime \prime}}$ pyrrole protons of BT1 and BT3 complexes displayed similar downfield chemical shifts because having similar lengths, HDC and BDC linkers pulled the adjacent pyridyl rings away from these protons. 


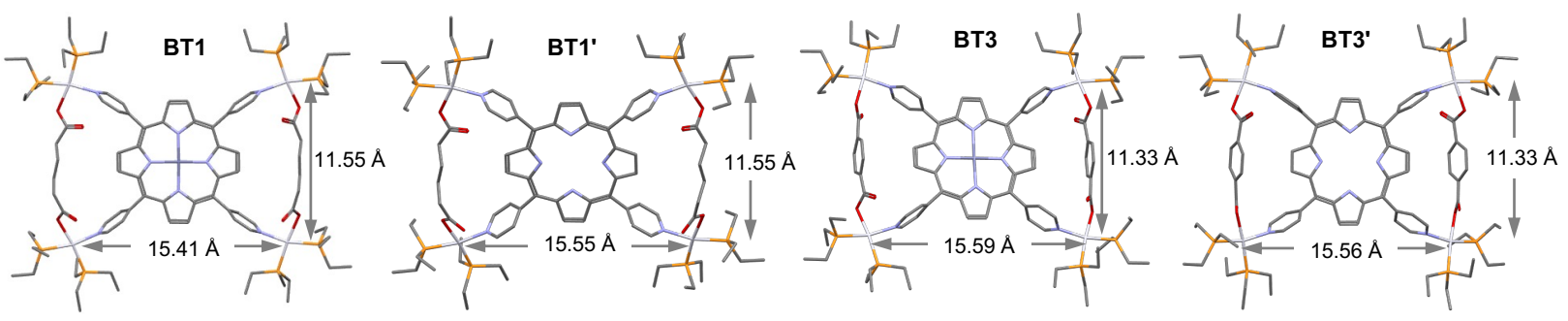

Fig. 6. The optimized structures of BT1, BT1', BT3, and BT3' complexes calculated by PM6 method.

Thus, the single-crystal and energy-minimized structures of M'TPP-based tricomponent SCCs demonstrated that regardless of the length (within the range of 6.9-11.2 $\AA$ ) and rigidity of the XDC linkers, the Pt(II)-driven self-assembly of M'TPP and XDC ligands exclusively yielded bow tie complexes instead of 3D prisms. This happened because the pyridyl arms of M'TPP ligands deviated from their original projections in order to incorporate the XDC linkers within the isosceles triangles of bow tie structures. Although previously reported M'TPP-based tricomponent SCCs based on rigid (e.g., isophthalate and BINOL-3,3'-dicarboxylate) ${ }^{33,34}$ and flexible (e.g., heptanedioate and octanedioate) ${ }^{33}$ XDC linkers have also displayed the same characteristic ${ }^{1}$ H NMR signals of bow tie complexes, i.e., two distinct singlets for the enclosed $\mathrm{H}_{\mathrm{c}^{\prime}}$ and exposed $\mathrm{H}_{\mathrm{c}^{\prime \prime}}$ pyrrole protons of the M'TPP core, they were incorrectly labeled as tetragonal prisms. In all those cases, the lengths of rigid XDC linkers were comparable to those employed here that actually formed bow tie complexes, while the longer flexible linkers, such as heptanedioate and octanedioate, ${ }^{33}$ bulged out like an arc to form $\infty$-shaped complexes instead of the proposed prisms. Therefore, more studies and compelling evidence are needed beyond just ESI-MS data to verify the prism formations. Beside M'TPP, another tetratopic ligand, 1,2-di(4-pyridyl)ethylene (DPE) was also used previously along with XDC linkers to construct tetragonal prisms. ${ }^{35,36,40}$ Since the angles of projection and dihedral angles of the pyridyl rings in DPE are different, it is plausible that it actually formed tetragonal prisms. However, in the light of the discovery of M'TPP-based bow tie complexes and better understanding of why M'TPP could not form tetragonal prisms with any XDC linkers, additional 2D NMR and X-ray crystallographic studies would be beneficial to verify the structures of other supramolecular prisms.

\section{CONCLUSION}

In summary, we have demonstrated that Pt(II)-driven social self-assembly of a tetratopic M'TPP ligand and ditopic XDC linkers having different lengths (6.9-11.2 $\AA$ ) and rigidities consistently yielded novel 2D bow tie complexes $\left[\left\{\left(\mathrm{Et}_{3} \mathrm{P}\right)_{2} \mathrm{Pt}\right\}_{4}\left(\mathrm{M}^{\prime} \mathrm{TPP}\right)(\mathrm{XDC})_{2}\right] \cdot(4 \mathrm{TfO})$ featuring a $\mathrm{M}^{\prime} \mathrm{TPP}$ core and two parallel XDC linkers that were held together by four heteroligated $\mathrm{Pt}^{\mathrm{II}}(\mathrm{N}, \mathrm{O})$ corners. The ${ }^{31} \mathrm{P}$ NMR spectra of the resulting tricomponent SCCs confirmed the formation of heteroleptic $\mathrm{Pt}^{\mathrm{II}}(\mathrm{N}, \mathrm{O})$ corners bearing one carboxylate and 
one pyridyl groups, while ${ }^{1} \mathrm{H}$ and 2D NMR studies presented telltale signs of their bow tie structures by revealing that two opposite pyrrole rings carrying the more shielded $\mathrm{H}_{\mathrm{c}^{\prime}}$ protons were located inside two isosceles triangles formed by two parallel XDC linkers, while the other two pyrrole rings bearing less shielded $\mathrm{H}_{\mathrm{c}^{\prime \prime}}$ protons remained exposed. The most direct and compelling evidence of bow tie complexes came from their single-crystal structures, which were fully consistent with their NMR characteristics. Our studies demonstrated that the pyridyl arms of M'TPP deviated from their original projections in order to accommodate different XDC linkers having different lengths $(\sim 7-11 \AA)$ and rigidity into isosceles triangles, which led to the formation of 4:1:2 bow tie complexes that were entropically more favored over $8: 2: 4$ tetragonal prisms. Thus, these comprehensive studies of M'TPP-based tricomponent SCCs not only unveiled novel bow tie complexes, but also demonstrated that M'TPP ligands are unable to form tetragonal prisms regardless of the length and rigidity dicarboxylate linkers. While the main focus of our fundamental studies presented here was to determine the accurate structures and compositions of M'TPP-based tricomponent SCCs, in the light of these revelations one could argue that some of the fascinating properties and functions, such as photodynamic cancer therapy that were previously attributed to prisms, actually belonged to bow tie complexes. Further studies of potential applications of these M'TPP-based bow tie complexes as light-harvesting and energy transduction systems are underway in our laboratory.

\section{Supporting Information}

Supporting Information containing experimental details and additional data available online at XXX. CCDC 2081606-2081610 contain crystallographic data, which can be obtained free of charge via www.ccdc.cam.ac.uk/data_request/cif.

\section{AUTHOR INFORMATION}

\section{*Corresponding Author}

Email: souravs@clemson.edu

\section{ORCID}

Sourav Saha: 0000-0001-6610-4820

Paola A. Benavides: 0000-002-1701-5036

M. Andrey Joaqui-Joaqui: 0000-001-7446-6004

\section{Note}

The authors declare no competing financial interest. 


\section{ACKNOWLEDGEMENTS}

This work was supported by the National Science Foundation (NSF award nos. CHE-1660329 and DMR1809092) and Clemson University. We also acknowledge the NSF-MRI grant CHE-1725919 for the 500 MHz NMR instrument used in our studies.

\section{REFERENCES}

1. M. Fujita, J. Yazaki and K. Ogura, J. Am. Chem. Soc., 1990, 112, 5645.

2. P. J. Stang and D. H. Cao, J. Am. Chem. Soc., 1994, 116, 4981.

3. P. J. Stang, B. Olenyuk, J. Fan, and A. M. Arif, Organometallics, 1996, 15, 904.

4. $\quad$ P. J. Stang and B. Olenyuk, Acc. Chem. Res., 1997, 30, 502.

5. A. J. Lees, and S.-S. Sun, Inorg. Chem., 2001, 40, 3154.

6. $\quad$ F. Würthner, C.-C. You and C. R. Saha-Möller, Chem. Soc. Rev., 2004, 33, 133.

7. N. C. Gianneschi, M. S. Masar III, and C. A. Mirkin, Acc. Chem. Res., 2005, 38, 825.

8. B. H. Northrop, Y.-R. Zheng, K.-W.Chi and P. J. Stang, Acc. Chem. Res., 2009, 42, 1554.

9. H. T. Chifotides, I. D. Giles and K. R. Dunbar, J. Am. Chem. Soc., 2013, 135, 3039.

10. M. A. Gordillo, P. A. Benavides and S. Saha, Cryst. Growth Des., 2019, 19, 6017.

11. K. Kumazawa, K. Biradha, T. Kusukawa, T. Okano, and M. Fujita, Angew. Chemie Int., Ed. 2003, 42, 3909.

12. R. Chakrabarty, P. S. Mukherjee and P. J. Stang, Chem. Rev., 2011, 111, 6810.

13. T. R. Cook, Y.-R. Zheng and P. J. Stang, Chem. Rev., 2013, 112, 734.

14. T. R. Cook and P. J. Stang, Chem. Rev., 2015, 115, 7001.

15. S. Zarra, D. M. Wood, D. A. Roberts and J. R. Nitschke, Chem. Soc. Rev., 2015, 44, 419.

16. S. Fujii, T. Tada, Y. Komoto, T. Osuga, T. Murase, M. Fujita and M. Kiguchi, J. Am. Chem. Soc., 2015, 137, 5939.

17. W. M. Bloch and G. H. Clever, Chem. Commun., 2017, 53, 8506.

18. T. K. Ronson, W. Meng and J. R. Nitschke, J. Am. Chem. Soc., 2017, 139, 9698.

19. W. Brenner, T. K. Ronson and T. K. Nitschke, J. Am. Chem. Soc., 2017, 139, 75.

20. S. Saha, I. Regeni and G. H. Clever, Coord. Chem. Rev., 2018, 374, 1.

21. S. Pullen and G. H. Clever, Acc. Chem. Res., 2018, 51, 3052.

22. S. Chakraborty and G. R. Newkome, Chem. Soc. Rev., 2018, 47, 3991.

23. D. Bardhan and D. Chand, Chem. Eur. J., 2019, 25, 12241.

24. S. Kitagawa, R. Kitaura and S. Noro, Angew. Chem. Int. Ed., 2004, 43, 2334.

25. W. L. Leong and J. J. Vittal, Chem. Rev., 2011, 111, 688.

26. H. Furukawa, K. E. Cordova, M. O'Keeffe and O. M. Yaghi, Science, 2013, 341, 974.

27. K. W. Chi, C. Addicott, A. M. Arif and P. J. Stang, J. Am. Chem. Soc., 2004, 126, 16569. 
28. M. Wang, Y.-R. Zheng, K. Ghosh, P. J. Stang, J. Am. Chem. Soc., 2010, 132, 6282.

29. Y. R. Zheng, W. J. Lan, M. Wang, T. R. Cook and P. J. Stang, J. Am. Chem. Soc., 2011, 133, 17045.

30. Y.-R. Zheng, Z. Zhao, M. Wang, K. Ghosh, J. B. Pollock, T. R. Cook and P. J. Stang, J. Am. Chem. Soc., 2010, 132, 16873.

31. M. Wang, Y.-R. Zheng, T. R. Cook and P. J. Stang, Inorg. Chem., 2011, 50, 6107.

32. J. B. Pollock, T. R. Cook, G. L. Schneider and P. J. Stang, Chem. Asian J., 2013, 8, 2423.

33. Y. Shi, I. Sánchez-Molina, C. Cao, T. R. Cook and P. J. Stang, Proc. Natl. Acad. Sci., 2014, 111, 9390.

34. Y. Ye, T. R. Cook, S. P. Wang, J. Wu, S. Li, and P. J. Stang, J. Am. Chem. Soc., 2015, 137, 11896.

35. X. Yan, T. R. Cook, P. Wang, F. Huang and P. J. Stang, Nature Chem., 2015, 7, 342.

36. G. Yu, T. R. Cook, Y. Li, X, Yan, D. Wu, L. Shao, J. Shen, G. Tang, F. Huang, X. Chen and P. J. Stang, Proc. Natl. Acad. Sci., 2016, 113, 13720.

37. Z. Li, X. Yan, F. Huang, H. Sepehrpour and P. J. Stang, Org. Lett., 2017, 19, 5728.

38. M. Zhang, M. L. Saha, M. Wang, Z. Zhou, B. Song, C. Lu, X. Yan, X. Li, F. Huang, S. Yin and P. J. Stang, J. Am. Chem. Soc., 2017, 139, 5067.

39. G. Yu, S. Yu, M. L. Saha, J. Zhou, T. R. Cook, B. C. Yung, J. Chen, Z. Mao, F. Zhang, Z. Zhou, Y. Liu, L. Shao, S. Wang, C. Gao, F. Huang, P. J. Stang and X. Chen, Nat. Commun., 2018, 9, 1.

40. Y. Sun, Y. Yao, H. Wang, W. Fu, C. Chen, M. L. Saha, M. Zhang, S. Datta, Z. Zhou, H. Yu, X. Li and P. J. Stang, J. Am. Chem. Soc., 2018, 140, 12819.

41. X. Chang, Z. Zhou, C. Shang, G. Wang, Z. Wang, Y. Qi, Z.-Y. Li, H. Wang, L. Cao, X. Li, Y. Fang and P. J. Stang, J. Am. Chem. Soc., 2019, 141, 1757.

42. X. Chang, Z. Zhou, C. Shang, G. Wang, Z. Wang, Y. Qi, Z. Y. Li, H. Wang, L. Cao, X. Li, Y. Fang and P. J. Stang, J. Am. Chem. Soc., 2019, 141, 1757.

43. Y. Sun, C. Chen, J. Liu and P. J. Stang, Chem. Soc. Rev., 2020, 49, 3889.

44. S. Ghosh and P. S. Mukherjee, Inorg. Chem., 2009, 48, 2605.

45. A. K. Bar, G. Mostafa and P. S. Mukherjee, Inorg. Chem., 2010, 49, 7647.

46. D. Samanta, S. Shanmugaraju, S. A. Joshi, Y. P. Patil, M. Nethaji and P. S. Mukherjee, Chem. Commun., 2012, 48, 2298.

47. C. García-Simón, M. Garcia-Borràs, L. Gómez, I. Garcia-Bosch, S. Osuna, M. Swart, J. M. Luis, C. Rovira, M. Almedia, I. Imaz, D. Maspoch, M. Costas and X. Ribas, Chem. Eur. J., 2013, 19, 1445.

48. C. García-Simón, M. Garcia-Borràs, L. Gómez, T. Parella, S Osuna, J. Juanhuix, I. Imaz, D. Maspoch, M. Costas and X. Ribas, Nat. Commun., 2014, 5, 5557.

49. C. Colomban, G. Szalóki, M. Allain, L. Gómez, S. Goeb, M. Sallé, M. Costas and X. Ribas, Chem. Eur. J., 2017, 23, 3016.

50. C. Colomban, V. Martin-Diaconescu, T. Parella, S. Goeb, C. García-Simón, J. Lloret-Fillol, M. Costas and X. Ribas, Inorg. Chem., 2018, 57, 3529.

51. C. Fuertes-Espinosa, A. Gómez-Torres, R. Morales-Martínez, A. Rodríguez-Fortea, C. GarcíaSimón, F. Gándara, I. Imaz, J. Juanhuix, D. Maspoch, J. M. Poblet, L. Echegoyen and X. Ribas, Angew. Chem. Int. Ed., 2018, 57, 11294. 
52. C. Colomban, C. Fuertes-Espinosa, S. Goeb, M. Sallé, M. Costas, L. Blancafort and X. Ribas, Chem. Eur. J., 2018, 24, 4371.

53. C. García-Simón, A. Monferrer, M. Garcia-Borràs, I. Imaz, D. Maspoch, M. Costas and X. Ribas, Chem. Commun., 2019, 55, 798.

54. V. Vajpayee, S. Bivaud, S. Goeb, V Croué, M. Allain, B. V. Popp, A. Garci, B. Therrien and M. Sallé, Organometallics., 2014, 33, 1651.

55. E. Ubasart, O. Borodin, C. Fuertes-Espinosa, Y. Xu, C. García-Simón, L. Gómez, J. Juanhuix, F. Gándara, I. Imaz, D. Maspoch, M. Delius and X. Ribas, Nat. Chem., 2021, DOI: 10.1038/s41557021-00658-6.

56. G. Yu, Y. Ye, Z. Tong, J. Yang, Z. Li, B. Hua, L. Shao and S. Li, Macromol. Rapid Commun., 2016, 37, 1540 .

57. Z. Zhao, Z. Zhang, H. Wang, X. Li and M. Zhang, Isr. J. Chem., 2019, 59, 299.

58. M. Eddaoudi, J. Kim, N. Rosi, D. Vodak, J. Wachter, M. O’Keeffe and M. Yaghi, Science, 2002, 295, 469.

59. S. Lipstman and I. Goldberg, Acta Cryst. Sect. C., 2009, 65, 371.

60. L. R. Dinelli, G. Von Poelhsitz, E. E. Castellano, J. Ellena, S. E. Galembeck and A. A. Batista, Inorg. Chem., 2009, 48, 4692. 
$\underline{\text { Table of Contents }}$

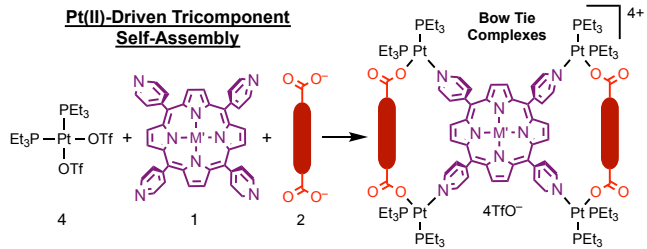

